\title{
Efficacy assessment of oral and sublingual sedation using alprazolam in implantology surgical procedures
}

\author{
Avaliação da eficácia da sedação por via oral e sublingual com \\ alprazolam em procedimentos cirúrgicos de Implantodontia
}

\author{
Antonio José Bittencourt da ROSA ${ }^{1}$ \\ Bruno Salles SOTTO-MAIOR ${ }^{2}$ iD 0000-0002-9462-0299 \\ Carlos Eduardo FRANCISCHONE ${ }^{3}$ \\ Juliana Cama RAMACCIATO4 ${ }^{4}$ 0000-0002-3081-1504 \\ Rui Barbosa de BRITO JÚNIOR ${ }^{5}$ iD 0000-0002-3484-9438 \\ Rogério Heládio Lopes MOTTA4 ${ }^{4}$ 0000-0002-6983-7883
}

\section{ABSTRACT}

Objective: The aim of this study was to evaluate the efficacy of two formulations of alprazolam (ALP) in patients undergoing oral implantology surgical procedures. Methods: A single-blinded randomized clinical study was performed with 52 volunteers (both genders) divided into 2 groups: $\mathrm{G} 1(\mathrm{n}=26)$ - oral administration of ALP $(0.5 \mathrm{mg}) 1 \mathrm{~h}$ before surgical procedures; and G2 $(\mathrm{n}=26)$ sublingual administration of ALP (0.5mg) 30 minutes before surgery. Blood pressure (BP) and heart rate (HR) were evaluated. Corah dental anxiety scale (COR), visual analogic scale (VAS), Trieger test (TRI) and the perception questionnaire (PQ) were used to assess the level of anxiety and responses to formulations, respectively. All parameters were evaluated at three times (be-fore, during and postoperative). Results: For BP and HR no statistically significant differences were observed between periods for G1 and G2 (p>0.05). For COR, most volunteers were classi-fied such as anxious or very anxious. For VAS, decreased anxiety was significant ( $p<0.05)$ and no statistically significant differences between the two groups both in the period "pre" $(p=0.18)$ and "post" $(p=0.12)$ were observed. For TRI, there were no significant differences between the periods considering the number of points lost ( $p>0.05)$. The anxiety reduction was significant $(p<0.05)$ for both formulations. As for PQ, both formulations showed good volunteers' acceptance ( $p>0.05)$, and they have not reported anterograde amnesia. Conclusion: It was concluded that both formulations were effective for sedation of the evaluated volunteers.

Indexing terms: Alprazolam. Conscious sedation. Dental implantation.

$\boldsymbol{\nabla} \boldsymbol{\nabla} \boldsymbol{\nabla}$

1 Faculdade São Leopoldo Mandic, Instituto de Pesquisas São Leopoldo Mandic, Área de Implantodontia. Campinas, SP, Brasil.

2 Universidade Federal de Juiz de Fora, Departamento de Odontologia Restauradora. Juiz de Fora, MG, Brasil.

3 Universidade de São Paulo, Faculdade de Odontologia de Bauru, Departamento de Dentística, Endodontia e Materiais Odontológicos. Bauru, SP, Brasil.

4 Faculdade São Leopoldo Mandic, Instituto de Pesquisas São Leopoldo Mandic, Área de Farmacologia, Anestesiologia e Terapêutica. Rua José Rocha Junqueira, 13, 13045-755, Campinas, SP, Brasil. Correspondência para / Correspondence to: RHL MOTTA. E-mail: <rogerio.motta@slmandic.edu.br>.

5 Faculdade São Leopoldo Mandic, Instituto de Pesquisas São Leopoldo Mandic, Área de Histologia. Campinas, SP, Brasil.

\section{$\boldsymbol{\nabla} \mathbf{v} \boldsymbol{\nabla}$}

Como citar estar artigo / How to cite this article

Rosa AJB, Sotto-Maior BS, Francischone CE, Ramacciato JC, Brito Junior RB, Motta RHL Efficacy assessment of oral and sublingual sedation using alprazolam in implantology surgical procedures. RGO, Rev Gaúch Odontol. 2019;67:e20190060. http://dx.doi.org/10.1590/198186372019000603516 


\section{RESUMO}

Objetivo: Avaliar a eficácia de duas formulações de alprazolam (ALP) na sedação de voluntários submetidos à procedimentos cirúrgicos de Implantodontia. Métodos: Foi realizado um estudo clinico, randomizado e cego, com 52 voluntários (ambos os gêneros) que foram divididos em 2 grupos: G1 (n=26) - administração de ALP (0,5mg) por via oral uma hora antes da sessão clínica; e G2 ( $n=26)$ administração de $\operatorname{ALP}(0,5 \mathrm{mg})$ por via sublingual 30 minutos antes da sessão clínica. Foram avaliadas a pressão arterial (PA) e frequência cardíaca (FC), e foram utilizadas a escala de ansiedade dental de Corah (COR) e escala analógica visual (EAV) para avaliação do nível de ansiedade. Adicionalmente, foram utilizados o teste de Trieger (TRI) e um questionário de percepção (QP) para avaliar as respostas aos tratamentos. Todos os parâmetros foram avaliados em 3 momentos (pré, trans e pós-operatório imediato). Resultados: Para PA e FC não foram observadas diferenças estatísticas significativas entre os períodos para G1 e G2 (p>0,05). Para COR, a maioria dos voluntários foi classificada como ansiosos ou muitos ansiosos em ambos os grupos ( $p>0,05)$, e para EAV a diminuição da ansiedade foi significativa $(p<0,05)$ e não houve diferença estatistica significativa entre os dois grupos tanto no período "pré" $(p=0,18)$ quanto no "pós" ( $p=0,12)$. Para TRI, não houve diferença significativa entre os períodos pré e pós considerando o número de pontos perdidos ( $p>0,05)$. Quanto ao QP, ambas as formulações tiveram boa aceitabilidade pelos voluntários ( $p>0,05)$, não ocorrendo amnésia anterógrada. Conclusão: Concluiu-se que ambas as formulações de alprazolam foram eficazes para a sedação dos voluntários avaliados.

Termos de indexação: Alprazolam. Sedação consciente. Implantação dentária.

\section{INTRODUCTION}

Fear and anxiety are routine problems in the dental clinic and dental treatment can be considered a crucial problem for odontophobic patients [1]. Fear of undergoing dental treatments or anxiety about these treatments is called by several authors as dental anxiety or odontophobia [2]. Literature has presented several terms concerning the patient's acceptance of the dental treatment, such as the fear of the treatment itself and dental anxiety, which is related to the fear of seeking and attending a dental office and phobia [3].

Fear and anxiety in dental treatment is worldwide. However, some subgroups present higher levels than others [4] which may lead to dental appointment avoidance, or yet only seek care in cases of pain [5]. Furthermore, odontophobic patients may be less cooperative during procedures and present less satisfaction with surgical treatments [6]

Dental surgical procedures such as the installation of dental implants are associated with high pain expectation, one of the main causes of anxiety [7] which can impair the pain control and trigger the need for larger amounts of anesthetics, analgesics and other medications [8]. Thus, it is of utmost importance that anxiety caused by dental treatment is reduced as well as other factors associated with anxiety such as pain expectations and previous negative experiences related to pre-surgical and trans-surgical anxiety [9].

Among the clinical options for anxiety control in Dentistry, oral sedation with benzodiazepines has been studied and recommended for dental procedures in anxious patients $[10,11]$. Taking into consideration the age range of patients treated in the area of Implantology, alprazolam may be a choice of treament due to its latency time and shorter half-life [11]. In addition, one research compared alprazolam pharmacokinetic and farmacodynamic parameters in the elderly and young adults, with only a small increase in plasma concentration in the elderly with no evidence of an increase in the effect of the drug [12] Meanwhile, oral administration of alprazolam can present some limitations, such as variable action time and effect delay [13]. Literature has discussed the search for new anxiolytics suggesting another sublingual formulation of alprazolam, which presents a shorter latency time as clinical advantage.

Within this context, a study has shown that sublingual alprazolam dosage obtained a higher plasma concentration peak (17.3 vs $14.9 \mathrm{ng} / \mathrm{ml}$ ) and a shorter time to reach it (1.17 vs 1.73 hours) when compared to the same orally taken dose (1 mg) [14]. It was concluded that alprazolam sublingual absorption is fast and a viable alternative for people with panic syndrome. For dental procedures, these drug features would allow its administration in a shorter time interval during the preoperative as well as in a controlled environment. However, further studies should be developed in order to evaluate the drug efficacy in Dentistry, mainly in Implantology. Thus, the aim of this study was to compare the efficacy of oral and sublingual alprazolam sedation in volunteers undergoing implantology surgical procedures. 


\section{METHODS}

This research was submitted and approved by the Research Ethics Committee of Faculdade São Leopoldo Mandic under protocol CAAE\# 30650314.3.0000.5374. The sample of this research consisted of 52 (fifty-two) volunteers, of both genders, mean age of $51.8( \pm 7.1)$ years, who sought for oral rehabilitation care.

The study was performed in patients requiring surgical intervention to install at least four implants in the same surgery or maxillary sinus surgeries. In the routine treatment of anxiety, alprazolam is used in doses of 0.5 to $0.75 \mathrm{mg}$ in adults and 0.25 to $0.5 \mathrm{mg}$ in the elderly [15]. Considering the doses available in the Brazilian market for both pharmaceutical formulations (oral and sublingual), the dose of $0.5 \mathrm{mg}$ was adopted for both formulations in the present study. Based on the above, the volunteers were divided into 2 groups: group $1(n=26)$ - oral administration of alprazolam $0.5 \mathrm{mg}$ tablet (Frontal ${ }^{\circledR}$, Pfizer) one hour before the clinical procedure, and group $2(n=26)$ - sublingual administration of alprazolam $0.5 \mathrm{mg}$ tablet (Frontal $\mathrm{SL}^{\circledR}$, Pfizer) 30 minutes before the clinical procedure.

The volunteers received detailed information about the study in order to obtain the informed consent form and were included according to the following inclusion and exclusion criteria: a) treatment plan accepted and in need of surgical procedures; b) volunteers classified as healthy during clinical anamnesis (ASA I or ASA II); c) ability to provide written consent; $d$ ) not use benzodiazepines or analgesics for a period of at least 15 days before surgeries; e) no contraindication to the use of the drugs proposed in the study (allergy, glaucoma, myasthenia gravis, pregnancy, among others). After volunteer's agreement of participation and signing of the consent term, a careful anamnesis was performed followed by a clinical chart completion and the volunteer's anxiety was evaluated by the Corah scale $[16,17]$.

Afterwards, the volunteers' vital signs (heart and respiratory rate, blood pressure and oxygen saturation) were monitored during the procedures at different moments (immediate preoperative period, after the first dental implant was installed or after access to the maxillary sinus, end of the procedure). Anxiety was also measured by visual analogue scale (VAS) before and after procedures. The VAS is characterized by a $10 \mathrm{~cm}$ straight line with no numbers except at the ends where 0 (zero) corresponds to "no anxiety" and 10 (ten) to "maximum intensity of anxiety". The classification was performed by placing a vertical mark on the line and the distance between the mark and the 0 end was measured by a digital caliper (Mitutoyo ${ }^{\circledR}$, USA), thus assessing the volunteer's anxiety level [18].

After the surgical procedure, the volunteers were also asked to respond to a questionnaire in order to evaluate their perception regarding the sedation method, the occurrence of anterograde amnesia and the presence of side effects. In addition, the Trieger test was used, which consists of joining points of a pre-established figure in two moments: in the immediate preoperative period and after the end of the procedures $[19,20]$. Additional information on surgical procedures was also recorded, such as number of implants installed, the place of the installation, time of surgery, number of anesthetic cartridge used and any complications during surgery.

For surgical procedures, local anesthesia was performed with lidocaine 2\% with epinephrine 1: 100,000 (Alphacaine ${ }^{\circledR}$, Nova DFL) for blocking the involved nerves or infiltrative technique in each case. The number of anesthetic cartidrges were recorded in the clinical form of each volunteer. Prophylactic antibiotic therapy (oral administration of $2 \mathrm{~g}$ of amoxicillin (Medley ${ }^{\circledR}$ ) and oral single dose of $4 \mathrm{mg}$ dexamethasone (Decadron ${ }^{\circledR}$, Aché) was administered one hour before the procedures as a drug protocol for all implant procedures. To control postoperative pain, ibuprofen $400 \mathrm{mg}$ (Alivium ${ }^{\circledR}$, Mantecorp) was administered every six hours for 2 days. For the other surgical procedures performed, the antibiotic prophylaxis was performed according to the patient's profile and procedure invasiveness $[21,22]$.

The results were initially submitted to Shapiro-Wilk and Bartlett test in order to observe the normality of the distribution and the similarity of the deviations, respectively. Normal distribution or similar deviations $(p<0.05)$ were not observed, and the data were submitted to non-parametric tests. The relative distribution of age, gender and other factors according to the studied groups was evaluated by the Mann-Whitney and Chi-square test.

Systolic and diastolic pressures, heart rate over time and the influence of treatments for each group (VAS values) were separately assessed by Friedman test, and the comparison between the groups was performed by the Mann-Whitney test. Trieger test parameters were evaluated by the Wilcoxon test for comparison between 
the pre and final periods and by Mann-Whitney test for evaluation between the groups. The volunteers' perception of the effect of the treatments was analyzed using Fisher's exact test and Chi-square test. All analyzes were performed considering a significance level of $5 \%$, using GraphPad Prism 6.0 and BioEstat 5.0 softwares.

\section{RESULTS}

As shown in table 1, no statistically significant differences ( $p>0.05$ ) between the groups concerning the surgical time required for the procedures, amount of local anesthetic used, gender and the systemic profile of the volunteers. Moreover, the type and characteristics of the procedure performed in each group did not present significant differences between the groups leading to sample homogeinity. The volunteers' distribution in each group considering the classification of anxiety, measured by Corah scale and age, was also homogeneous.

Figure 1 shows the results obtained for systolic and diastolic blood pressure in relation to the administered formulations.

It was observed that the systolic pressure decreased (Friedman test, $\mathrm{p}<0.05$ ) over time for both groups. In fact, the mean difference ( \pm standard deviation) between the measurements obtained in the period pre and pos showed a $5 \%$ reduction in the systolic pressure. The mean difference between the pre and final periods was $-6.8 \%$

Table 1. Relative distribution of gender and other factors according to the studied groups.

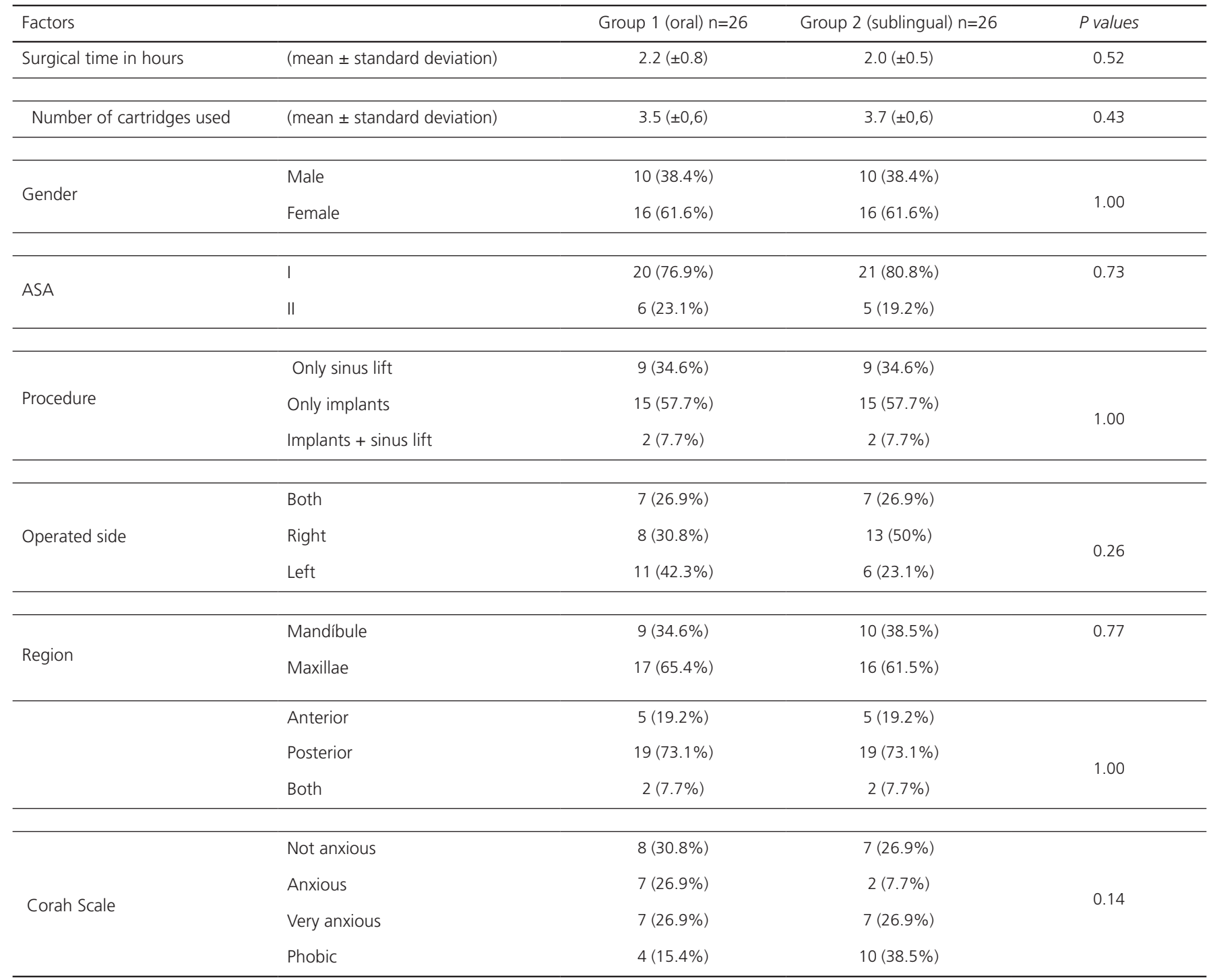




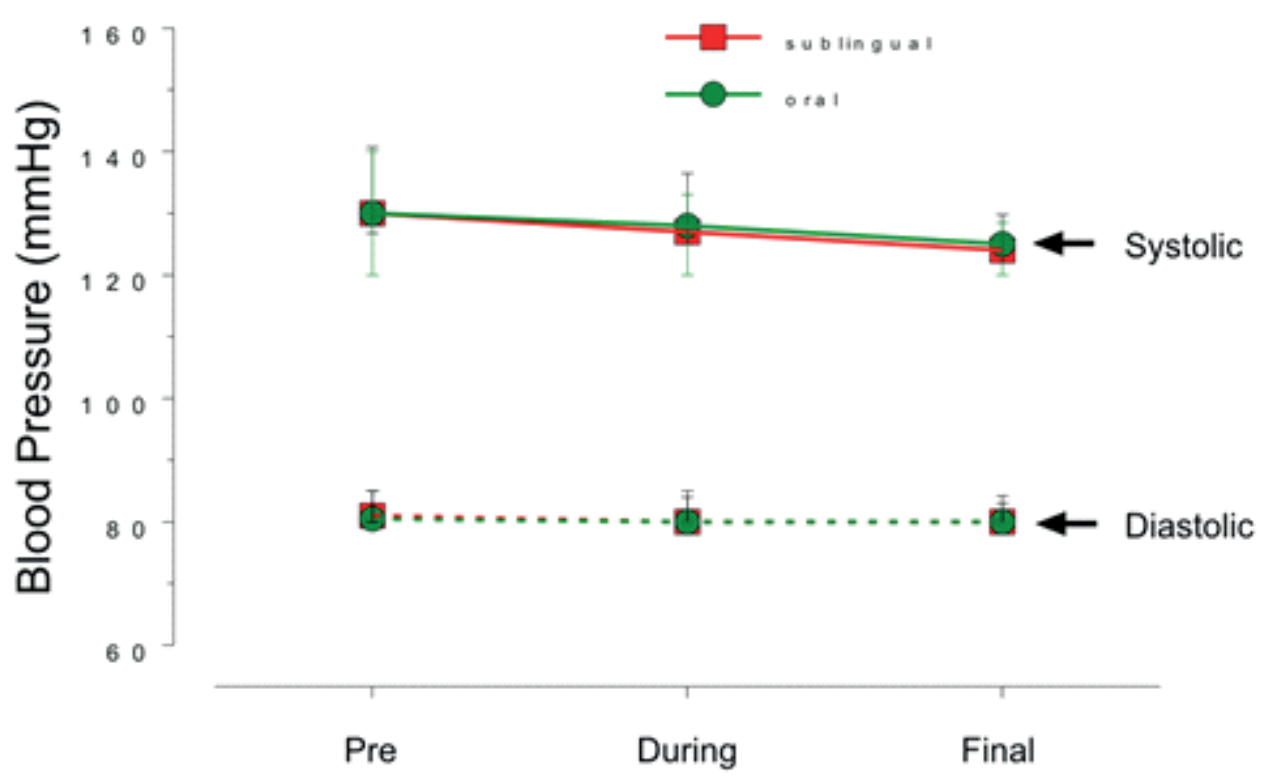

Figure 1. Median (interquartile range) of systolic arterial pressures (filled lines) and diastolic (dashed lines) according to groups and verification periods.

$( \pm 7.1 \%)$ and $-9.1 \%( \pm 7.8 \%)$, respectively for groups 1 and 2 . In addition, the comparison among the mean differences showed no statistically significant differences (Kruskal-Wallis test, $\mathrm{p}>0.05$ ) between the groups. It was also observed that, considering the systolic pressure found before $(p=0.61)$, trans $(p=0.65)$ or at the end of the procedures $(p=0.87)$, there was no statistically significant difference Mann-Whitney between the two groups.
Regarding diastolic blood pressure, it was observed that for both groups there was no significant statistical difference between the periods (Friedman test, $p>0.05)$. Furthermore, no significant statistical differences (Mann-Whitney test) were observed between the two groups, considering the diastolic pressure before $(p=0.53)$, trans $(p=0.90)$ or at the end of the procedures $(p=0.78)$. Actually, the differences between the diastolic pressures

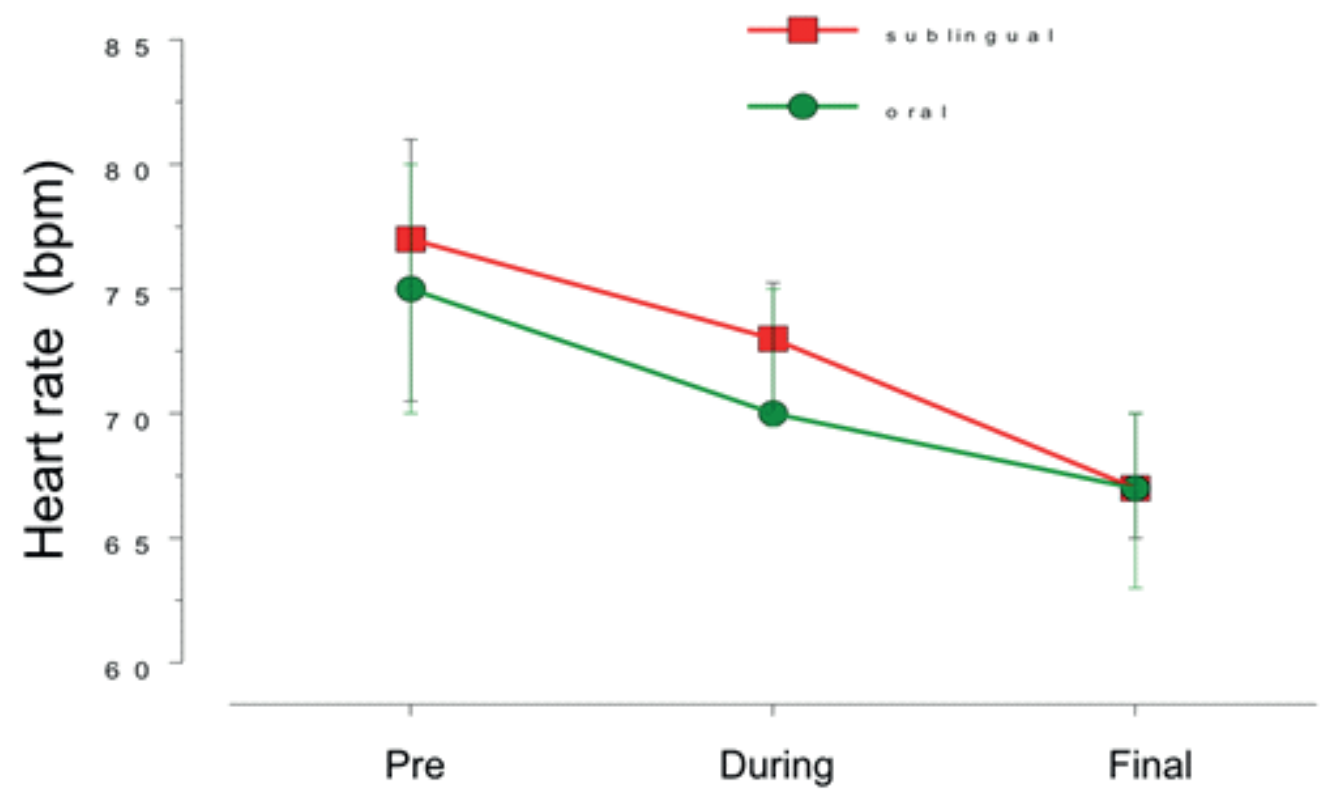

Figure 2. Median (interquartile range) of heart rate according to groups and periods of verification. 
measured in the pre-period and the others showed a 1.5\% reduction or less. Thus, there was no significant blood pressure change for both alprazolam formulations.

Figure 2 shows the effects of the two treatments over the periods evaluated regarding heart rate. It was observed that there was a decrease (Friedman test, $\mathrm{p}<0.05$ ) over time, for both groups. Nonetheless there was no significant statistical difference (Mann-Whitney test) between the two groups either before $(p=0.95)$, during $(p=0.41)$ or at the end of the procedures $(p=0.93)$. Thus, there was no difference between the effects of treatments on heart rate.

Figure 3 shows the influence of treatments on anxiety measured by VAS in two different periods. The anxiety reduction was very significant (Friedman test, $p<0.0001$ ) between the "pre" and "final" periods for groups 1 and 2 . However, there was no statistical significant difference between the two groups in both "pre" $(p=0.18)$ and "final" $(p=0.12)$ periods. Thus, both treatments caused significant reduction of anxiety (measured by VAS). Nonetheless, no difference was found between alprazolam formulations.

The treatment effects on individuals' alertness was assessed by the time (figure 4) spent to complete the
Trieger test, as well as by the number of lost points (figure 5) when filling the same test. There were no statistical significant differences (Wilcoxon test) between the pre and final periods, considering the number of points lost for both group $1(p=0.07)$ and group $2(p=0.06)$ and neither between groups 1 and 2 (Mann-Whitney test), both for the pre $(p=0.48)$ and final $(p=0.92)$ periods. However, the time spent filling the test was significantly lower (Wilcoxon's test) in the final period for both group 1 $(p=0.01)$ and group $2(p<0.0001)$, although no statistical significant differences (Mann-Whitney test) were found between the groups, both in the pre- $(p=0.84)$ and in the post-procedure periods $(p=0.29)$.

Table 2 shows the volunteers's perception regarding the different forms of alprazolam effects. The analysis of the data revealed that there was no statistically significant difference between the treatments in relation to the procedure recall and most of the volunteers reported that remembered the whole procedure. Moreover, although no differences were observed between the groups regarding previous experiences, most volunteers pointed out that they felt a lot of difference compared to previous dental procedures. More drowsiness was reported in the volunteers of group 2 than in group 1.

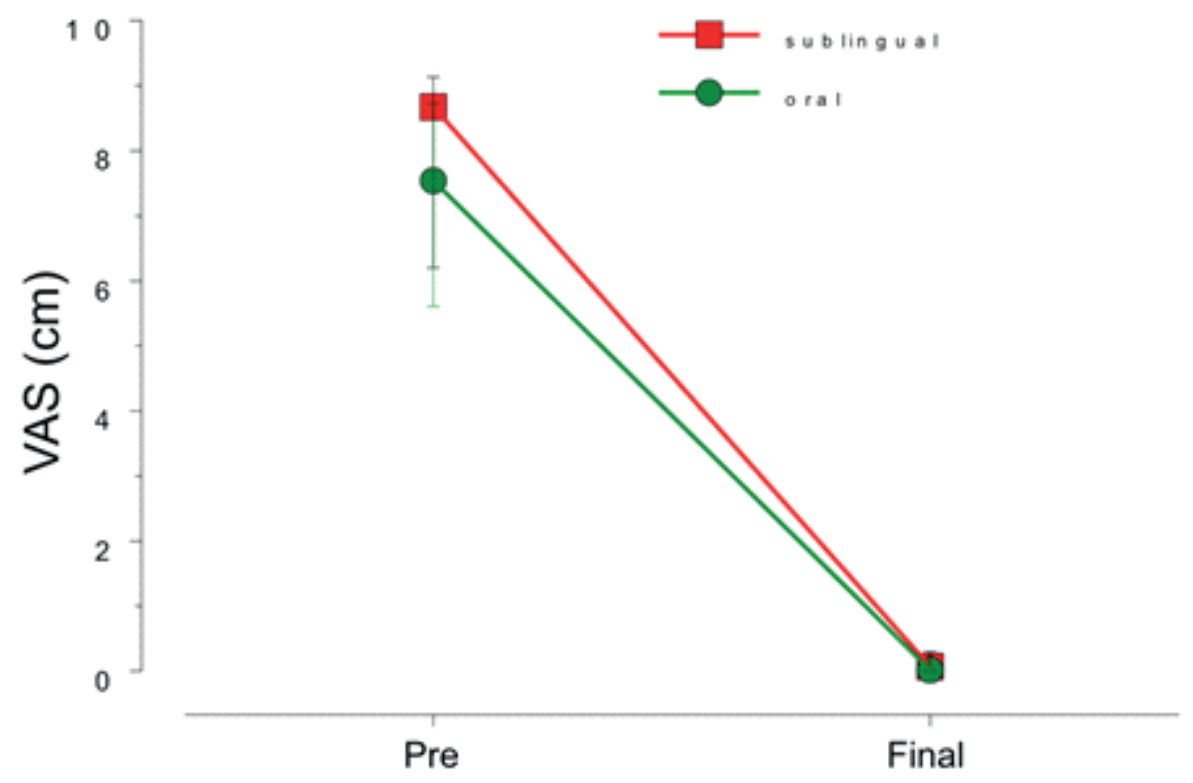

Figure 3. Median (interquartile range) of anxiety (measured by VAS) according to the groups and the periods assessed. 


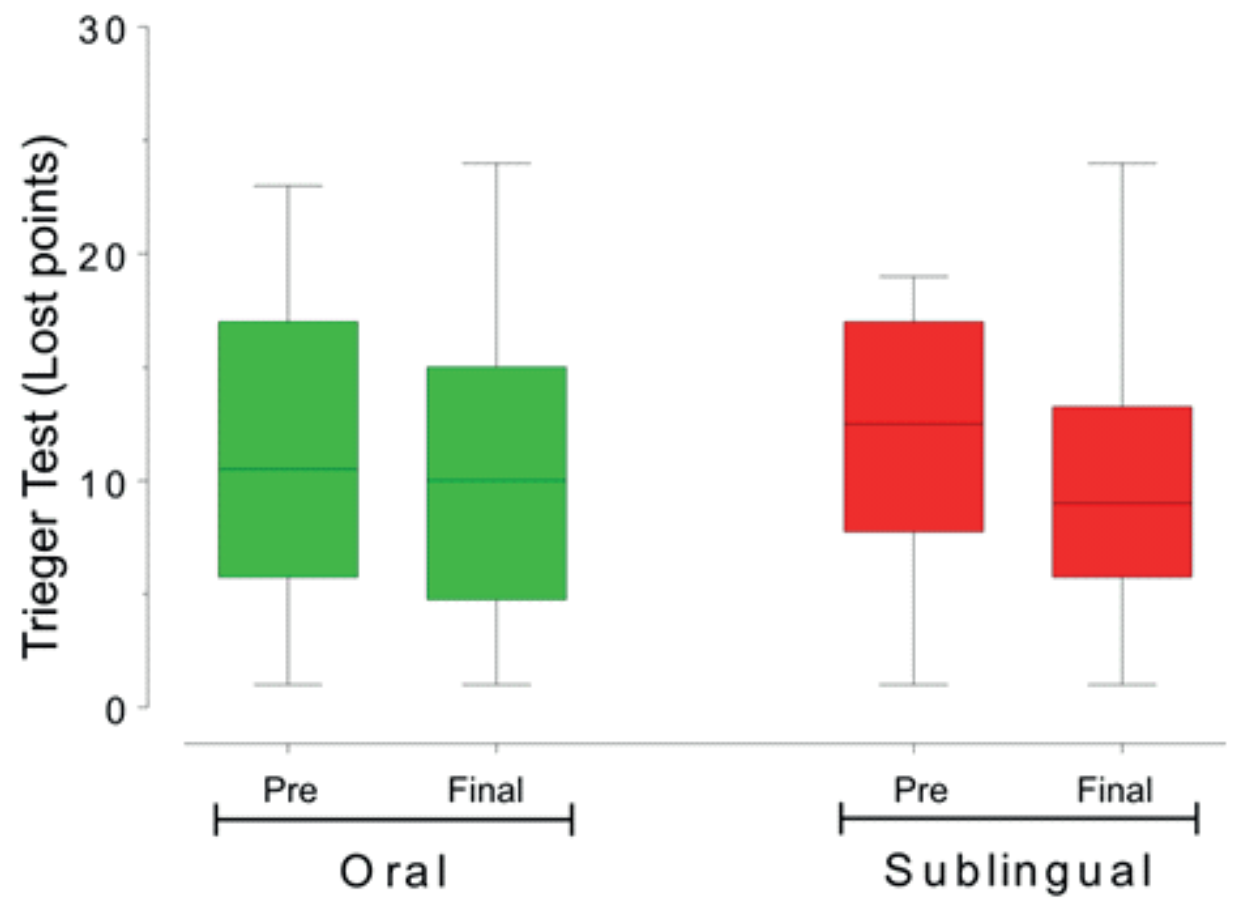

Figure 4. Number of lost points during the completion of the Trieger test according to the groups and the evaluation periods. The center line represents the median, the box represents the $1^{\text {st }}$ and $3^{\text {rd }}$ quartiles and the whiskers show the minimum and maximum values.

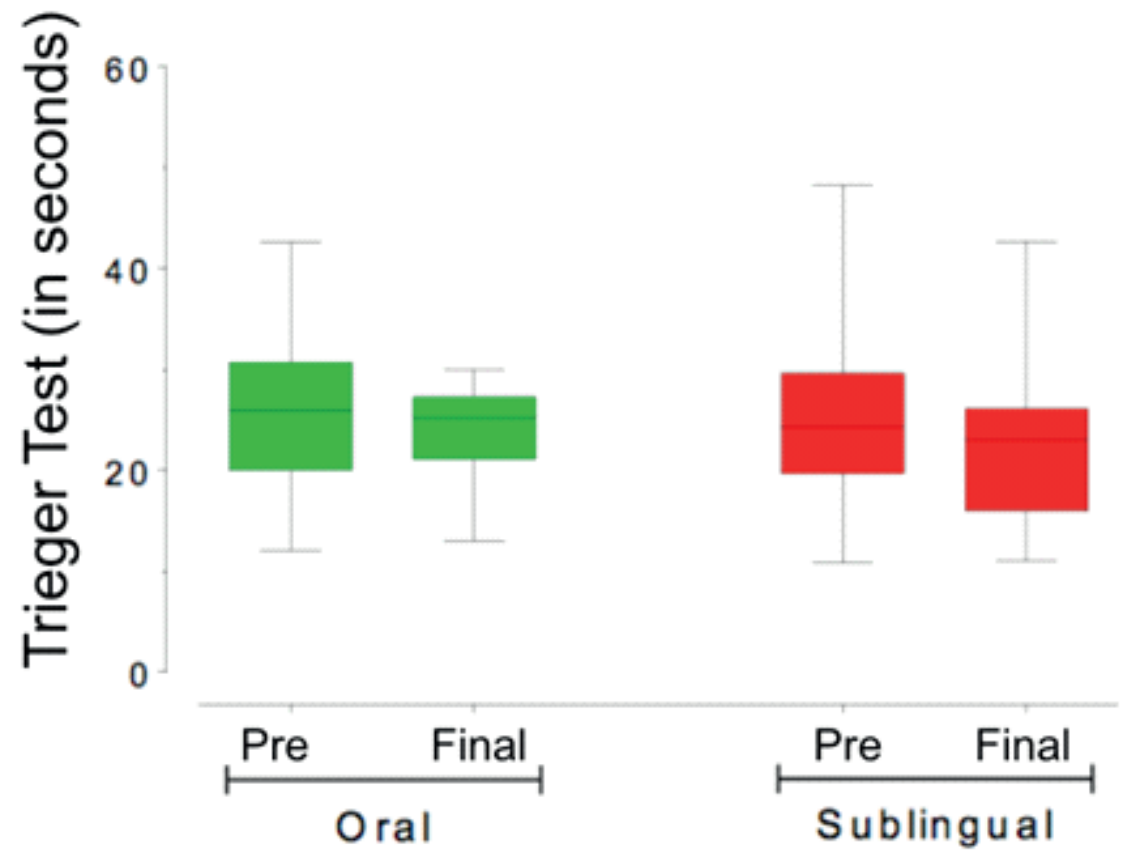

Figure 5. Time spent (in seconds) during the completion of the Trieger test according to the groups and the verification periods. The center line represents the median, the box represents the $1^{\text {st }}$ and $3^{\text {rd }}$ quartiles and the whiskers show the minimum and maximum values. 
Table 2. Volunteers' perception on sedation induced by treatments.

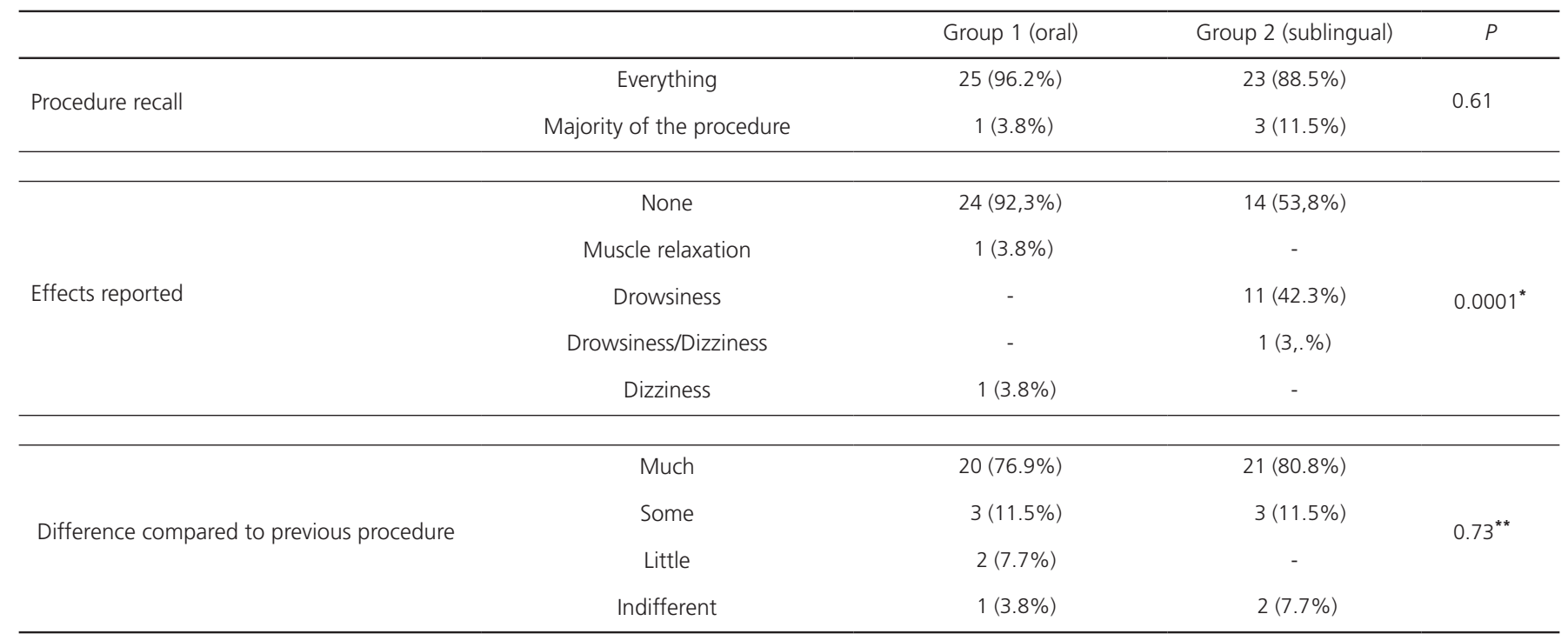

Note: ${ }^{*}$ Comparison between none and drowsiness. ${ }^{* *}$ Comparison between " much " and all the other classifications together.

\section{DISCUSSION}

Benzodiazepines are commonly drugs used orally in Dentistry due to their efficacy and safety, since it has an effective reverser and present good patient acceptability $[10,13,21]$. Nonetheless, there have been few clinical studies concerning the sublingual use of these drugs in dental procedures, which has led the present study.

Regarding drug administration, sublingual alprazolam is expected to provide a faster action onset and greater bioavailability than oral administration due to its rapid absorption and first passmetabolism avoidance. Scavone et al. [20] compared alprazolam when administered orally or sublingually and found a higher plasma concentration with the sublingual route, although the differences have not shown statistical significance. The benzodiazepine sublingual administration has proved better intake over oral administration due to its increased bioavailability and to faster promote higher blood concentration [23-25].

The analysis of the variables such as age, surgical time, cartidges number used, gender, systemic condition (ASA classification), operated region (side, posterior or anterior, upper or lower) showed procedure homogenization and no interference with results, which is an important issue in the present study [26]. The result of the patients' anxiety profile analysis demonstrated the predominance of anxious and very anxious individuals, regardless of age and gender. This corroborates with different authors $[7,27,29]$, who observed a predominance of anxious patients in several dentistry specialties.

In the present study, the anxiety reduction between the pre- and postoperative period was also very significant with the administration of both alprazolam formulations, suggesting that the two formulations were effective in the anxiety control of the evaluated volunteers. This result corroborates with Wolf et al. [30] who observed anxiety reduction in volunteers with doses of $0.25 \mathrm{mg}$ and $1 \mathrm{mg}$ of alprazolam when compared to placebo. In addition, systolic and heart rate values were decreased and diastolic pressure remained stable, according to Joshi et al. [31], who observed the stability of vital signs and reduction of anxiety for the dose of $0.5 \mathrm{mg}$ for pre-medication in oral surgery.

A possible hypothesis for this arterial pressure decrease would be the more controlled response of adrenaline and noradrenaline during the stress, confirming the findings of Van den Berg et al. [32], who suggested that alprazolam presents specific adrenomedullary suppression activity. These results demonstrate the clinical safety of alprazolam at the dose of $0.5 \mathrm{mg}$ in the preoperative period, besides providing adequate maintenance of the vital signs during the clinical procedures, corroborating with several authors $[10,11,13]$.

The use of the Corah scale chosen to evaluate patients' fear and anxiety is well publicized in the literature 
and its reliability and validity are supported by several studies $[16,17,33]$. Moreover, visual analogue scale (VAS) has been used in studies for many years and has been confirmed as an effective method to evaluate the volunteers' anxiety [18].

The Trieger test was chosen as assessment for evaluating the effect of two routes of administration on motor coordination, since it has been widely used and recommended as a method of evaluating post-sedation responsiveness for patient release $[19,20]$. The evaluation of the results obtained by the Trieger test shows that the motor coordination recovery was similar when the two administration routes were compared. However, the time taken to complete the test was significantly lower in the final period for the two routes, indicative of increased motor coordination of the patient due to the control / reduction of preoperative anxiety. Thus, the results have suggested that both formulations provide a rapid recovery of the patient, probably due to their shorter half-life, which $s$ one of the reasons for their clinical indication for elderly patients $[11,13,21]$.

Regarding the volunteers' perception, they reported presenting no undesirable side effects, and most of them would choose to take alprazolam again if they needed a new dental procedure. Furthermore, most volunteers reported that they remembered the whole procedure. Additionally, for the formulation of alprazolam administered by the sublingual route, some of the volunteers reported drowsiness, which can be explained by the lower latency of the drug $[30,31,34]$.

Although volunteers reported more drowsiness with this formulation, the results of the Trieger test demonstrate the patient's rapid recovery, which suggests the clinical feasibility of this formulation for Implantology clinical procedures. It is also essential to highlight that no evaluated formulation presented adverse reactions and intercurrences, demonstrating that the clinical safety of this type of benzodiazepine in clinical procedures $[13,35]$. Considering the profile of the patients evaluated, the results obtained in the present study suggest that both alprazolam formulations may be viable clinical options for surgical procedures in Implantology. Considering the importance of the subject and the scarcity of similar studies, new studies should be carried out in order to more demonstrate the use of alprazolam for surgical Implantology procedures.

\section{CONCLUSION}

It was concluded that both formulations of alprazolam were effective for the sedation of the volunteers evaluated.

\section{Collaborators}

AJB DA ROSA is the principal investigator and led the writing of the manuscript. JC RAMACCIATO and RHL MOTTA are the project managers, co-investigators and contributed to the writing and revision of the manuscript. CE FRANCISCHONE, BS SOTTO-MAIOR and RB BRITO JUNIOR are cO-investigators and contributed to the writing and revision of the manuscript.

\section{REFERENCES}

1. Candido MC, Andreatini R, Zielak JC, de Souza JF, Losso EM. Assessment of anxiety in pa-tients who undergo surgical procedures for tooth implants: a prospective study. Oral Maxillofac Surg. 2015 Sep;19(3):253-8. http://dx.doi. org/10.1007/s10006-014-0480-3

2. Crofts-Barnes NP, Brough E, Wilson KE, Beddis AJ, Girdler NM. Anxiety and quality of life in phobic dental patients. J Dent Res. 2010 Mar;89(3):302-6. http://dx.doi. org/10.1177/0022034509360189

3. Armfield JM. Predicting dental avoidance among dentally fearful Australian adults. Eur J Oral Sci. 2013 Jun;121(3 Pt 2):240-6. http://dx.doi.org/10.1111/eos. 12036

4. Carter AE, Carter G, Boschen M, AlShwaimi E, George R. Pathways of fear and anxiety in dentistry: A review. World J Clin Cases. 2014 Nov; 2(11):642-53. http://dx.doi. org/10.12998/wjcc.v2.i11.642

5. Armfield JM, Stewart JF, Spencer AJ. The vicious cycle of dental fear: exploring the interplay between oral health, service utilization and dental fear. BMC Oral Health. 2007 Jan 14;7:1. http://dx.doi.org/10.1186/1472-6831-7-1

6. González-Lemonnier S, Bovaira-Forner M, Peñarrocha-Diago M, Peñarrocha-Oltra D. Relationship between preoperative anxiety and postoperative satisfaction in dental implant surgery with intravenous conscious sedation. Med Oral Patol Oral Cir Bucal. 2010 Mar 1;15(2):e379-82. http://dx.doi. org/10.4317/medoral.15.e379

7. Oosterink FM, de Jongh A, Aartman IH. What are people afraid of during dental treatment? Anxiety-provoking capacity of 67 stimuli characteristic of the dental setting. Eur J Oral Sci. 2008 Feb;116(1):44-51. http://dx.doi.org/10.1111/j.1600-0722.20 07.00500.x

8. Eli I, Schwartz-Arad D, Bartal Y. Anxiety and ability to recognize clinical information in dentis-try. J Dent Res. 2008 Jan;87(1):65-8. http://dx.doi.org/10.1177/154405910808700111

9. Lino PA, Martins MAP, Silva MESE, de Abreu MHNG. Anxiolytics, Sedatives, and Hypnotics Prescribed by Dentists in Brazil in 
2010. Biomed Res Int. 2017;2017:2841549. http://dx.doi. org/10.1155/2017/2841549

10. Corcuera-Flores JR, Silvestre-Rangil J, Cutando-Soriano A, López-Jiménez J. Current methods of sedation in dental patients - a systematic review of the literature. Med Oral Patol Oral Cir Bucal. 2016 Sep 1;21(5):e579-86. http://dx.doi. org/10.4317/medoral.20981

11. Cogo K, Bergamaschi CC, Yatsuda R, Volpato MC, Andrade ED. Sedação consciente com benzodiazepínicos em odontologia. Rev Odontol Univ São Paulo. 2006;18(2)181-8.

12. Kaplan GB, Greenblatt DJ, Ehrenberg BL, Goddard JE, Harmatz JS, Shader RI. Single-dose pharmacokinetics and pharmacodynamics of alprazolam in elderly and young subjects. J Clin Pharmacol. 1998 Jan;38(1):14-21. http://dx.doi. org/10.1002/j.1552-4604.1998.tb04370.x

13. Haas DA. Oral sedation in dental practice. Royal College of Dental Surgeons of Ontario; 2015.

14. Scavone JM, Greenblatt DJ, Shader RI. Alprazolam kinetics following sublingual and oral administration. J Clin Psychopharmacol. 1987 Oct;7(5):332-4. http://dx.doi.org/10. 1097/00004714-198710000-00008

15. Matear DW, Clarke D. Considerations for the use of oral sedation in the institutionalized geriatric patient during dental interventions: a review of the literature. Spec Care Dentist. 1999 Mar-Apr;19(2):56-63. http://dx.doi.org/10.1111/j.1754-45 05.1999.tb01369.x

16. Corah NL. Development of a dental anxiety scale. J Dent Res. 1969 Jul-Aug;48(4):596. http://dx.doi.org/10.1177/002203 45690480041801

17. Corah NL, Gale EM, Illig SJ. Assessment of a dental anxiety scale. J Am Dent Assoc. 1978 Nov;97(5):816-9. http://dx.doi. org/10.14219/jada.archive.1978.0394

18. Facco E, Zanette G, Favero L, Bacci C, Sivolella S, Cavallin $F$, et al. Toward the validation of visual analogue scale for anxiety. Anesth Prog. 2011 Spring;58(1):8-13. http://dx.doi. org/10.2344/0003-3006-58.1.8

19. Trieger N, Newman MG, Miller JC. An objective measure of recovery. Anesth Prog. 1969 Jan;16(1):4-7.

20. Newman MG, Trieger N, Miller JC. Measuring recovery from anesthesia-a simple test. Anesth Analg. 1969;48(1):136-40.

21. Andrade ED. Terapeutica Medicamentosa na Odontologia. $3^{\text {a }}$ ed. São Paulo: Artes Médicas; 2014.

22. Resnik RR, Misch C. Prophylactic antibiotic regimens in oral implantology: rationale and protocol. Implant Dent. 2008 Jun;17(2):142-50. http://dx.doi.org/10.1097/ID.0b013e3181 $752 \mathrm{~b} 09$

23. Berthold CW, Dionne RA, Corey SE. Comparison of sublingually and orally administered tria-zolam for premedication before oral surgery. Oral Surg Oral Med Oral Pathol Oral Radiol Endod. 1997 Aug;84(2):119-24. http://dx.doi.org/101016/ s1079-2104(97)90055-x
24. Shavakhi A, Soleiman S, Gholamrezaei A, Khodadoostan M, Shavakhi S, Tahery A, et al. Premedication with sublingual or oral alprazolam in adults undergoing diagnostic upper gastrointestinal endoscopy. Endoscopy. 2014;46(8):633-9. http://dx.doi.org/10.1055/s-0034-1377305

25. Woolgrove J, Cumberbatch G. Dental anxiety and regularity of dental attendance. J Dent. 1986 Oct;14(5):209-13. http:// dx.doi.org/10.1016/0300-5712(86)90003-5

26. Vassend O. Anxiety, pain and discomfort associated with dental treatment. Behav Res Ther. 1993 Sep;31(7):659-66. http://dx.doi.org/10.1016/0005-7967(93)90119-f

27. de Carvalho RW, Falcão PG, Campos GJ, Bastos Ade S, Pereira $J C$, Pereira MA, et al. Anxiety regarding dental treatment: prevalence and predictors among Brazilians. Cien Saude Colet. 2012 Jul;17(7):1915-22. http://dx.doi.org/10.1590/S14 13-81232012000700031

28. Newton JT, Buck DJ. Anxiety and pain measures in dentistry: a guide to their quality and ap-plication. J Am Dent Assoc. 2000 Oct;131(10):1449-57. http://dx.doi.org/10.14219/jada.archive. 2000.0056

29. Dailey YM, Humphris GM, Lennon MA. The use of dental anxiety questionnaires: a survey of a group of UK dental practitioners. Br Dent J. 2001 Apr 28;190(8):450-3. http://dx.doi. org/10.1038/sj.bdj.4801000

30. Wolf DL, Desjardins PJ, Black PM, Francom SR, Mohanlal RW, Fleishaker JC. Anticipatory anxiety in moderately to highly-anxious oral surgery patients as a screening model for anxiolytics: evaluation of alprazolam. J Clin Psychopharmacol. 2003 Feb;23(1):51-7. http://dx.doi.org/10.1097/00004714-2 00302000-00009

31. Joshi S, Ansari AS, Mazumdar S, Ansari S. A comparative study to assess the effect of oral alprazolam as premedication on vital parameters of patients during surgical removal of impacted mandibular third molars. Contemp Clin Dent. 2016 Oct-Dec;7(4):464-468. http://dx.doi.org/10.4103/0976-237X. 194125

32. Van Den Berg F, Tulen JH, Boomsma F, Noten JB, Moleman P, Pepplinkhuizen L. Effects of alprazolam and lorazepam on catecholaminergic and cardiovascular activity during supine rest, mental load and orthostatic challenge. Psychopharmacology (Berl). 1996 Nov;128(1):21-30. http:// dx.doi.org/10.1007/s002130050105

33. Sharma A, Pant R, Priyadarshi S, Agarwal N, Tripathi S, Chaudhary M. Cardiovascular Changes Due to Dental Anxiety During Local Anesthesia Injection for Extraction. J Maxillofac Oral Surg. 2019 Mar;18(1):80-87. http://dx.doi.org/10.1007/s12 663-018-1085-4

34. Standards for Conscious Sedation in the Provision of Dental Care. The dental faculties of the royal colleges of surgeons and the Royal College of Anaesthetists. 2015.

35. Donaldson M, Gizzarelli G, Chanpong B. Oral sedation: a primer on anxiolysis for the adult patient. Anesth Prog. 2007;54(3):118-28. http://dx.doi.org/10.2344/0003-3006

Received on: 15/2/2019 Final version resubmitted on: 8/5/2019 Approved on: 20/5/2019 